\title{
Configuring effective client-adviser interactions
}

\begin{abstract}
A critical mechanism to achieve interorganizational trust is the development of trust at the interpersonal level, when representatives of partner organizations interact. The purpose of this study is to further illuminate the conditions under which interpersonal trust develops in organizational settings. Drawing on data from a survey of clients of different financial services providers, this study performs a fuzzy-set qualitative comparative analysis to better understand and describe interpersonal trust-enhancing mechanisms. This inquiry focuses on factors of three important domains: communication style, interactant stereotypes, and interaction structure. The results of the analysis offer insights into the necessary and sufficient conditions for trust, thus advancing current debates by uncovering important hygiene factors of trust and delineating interesting complementarity effects among factors of three different domains.
\end{abstract}

Keywords: Trust, Services, Client-adviser relationship, fsQCA 


\section{Introduction}

The functioning and performance of interorganizational relationships greatly depend on the governance mechanisms that relationship partners build and rely on while they interact. An important relational governance mechanism that has received strong interest in interorganizational contexts and has been highlighted as a key dimension of relationship quality is trust (e.g., Paulssen, Leischnig, Ivens, \& Birk, 2016; Zaheer \& Venkatraman, 1995). Trust denotes the confidence in an exchange partner's reliability and integrity (Palmatier, Dant, Grewal, \& Evans, 2006) and refers to the "expectation that an exchange partner will not behave opportunistically, even when such behavior cannot be detected by the victim" (Puranam \& Vanneste, 2009, p. 11).

Trust research examines the concept from different theoretical perspectives and makes a broad distinction between individual-level and organizational-level perspectives on trust (e.g., Jap \& Anderson, 2003; Schoorman, Mayer, \& Davis, 2007; Zheng, Hui, \& Yang, 2017). Trust can exist at different organizational levels (Fang, Palmatier, Scheer, \& Li, 2008), and the formation of trust between organizations involves a multi-stage process characterized by crosslevel effects (Schilke \& Cook, 2013). One of the central stages of this process is the development of interpersonal trust between representatives of the interacting organizations. Interpersonal trust, as developed through interactions between representatives, acts as an indicator of trustworthiness of the partner organization, thus facilitating a trust transfer process from the individual level to the organizational level.

The purpose of this article is to further illuminate this stage of the trust formation process by delineating the mechanisms that contribute to the development of interpersonal trust between representatives of the interacting organizations. Drawing from and integrating literature streams 
on trust-enhancing mechanisms, this study conducts an exploratory configurational analysis in an attempt to unpack how factors of three important domains (i.e., communication style, interactant stereotypes, and interaction structure) work together to enhance interpersonal trust. This study thus responds to recent calls for trust research that embraces configuration theoretical considerations and approaches (Woodside, 2019). Drawing on data from a survey of clients of financial services providers, this study performs a configurational analysis using fuzzy-set qualitative comparative analysis (fsQCA) (Ragin, 2008) to better understand the interplay among communication-related, interactant-related, and interaction structure-related factors for achieving high trust and to contribute to the development of intra-entity trust in organizational settings.

The results of the analysis indicate that a high level of perceived employee competence and the absence of communication fuzziness are necessary conditions for high trust. Furthermore, the results of the analysis reveal alternative configurations of conditions that are consistently sufficient for high trust. The configurations differ in their particular composition and their empirical relevance. However, each configuration represents a pathway to high interpersonal trust. Knowledge of the configurations is important because they offer insights into the reinforcing effects between factors of different theoretical domains in enhancing trust. From a managerial perspective, the configurations offer choices for managers regarding the design of trust-enhancing interaction approaches. Overall, the findings of the analyses contribute to the trust literature by advancing the understanding of intra-entity trust and by delineating trustenhancing mechanisms; they also illuminate multiple realities of the phenomenon (Woodside, 2014). These insights offer guidance for the management of client-adviser interactions, especially on the training of financial services advisers and the design of trust-enhancing interaction approaches. 
The rest of this article proceeds as follows: the next section outlines the conceptual background and briefly explains the focal concepts of this study. Then, the article discusses the research approach with a focus on data collection and data analysis procedures. After that, attention turns to the findings of the analysis. The article concludes with a discussion of theoretical contributions and managerial implications.

\section{Conceptual background}

Prior work establishes that trust is a key factor in business relationships (Morgan \& Hunt, 1994). A high level of trust increases a focal actor's belief that an exchange partner will keep its promises and fulfill its responsibilities (Scheer \& Stern, 1992). Thus, trust-based relationships show higher stability (Achrol \& Stern, 1988), which in turn promotes a long-term orientation of the relationships (Ganesan, 1994). In addition, trust reduces conflicts and facilitates collaboration (Anderson \& Narus, 1990), which can lead to enhanced relationship performance outcomes (Gulati \& Nickerson, 2008). As an "important lubricant of the social system" (Arrow, 1974, p. 23 ), trust is therefore essential for the functioning of relationships.

Trust can develop at different organizational levels (Fang et al., 2008), and it emerges from and grows through cross-level effects and interactions over time (Gulati, 2007; Schilke \& Cook, 2013). As firms work to develop a close relationship with another organization, they rely on building trust at different levels (Smith, Carroll, \& Ashford, 1995). One of the key stages in the trust formation process is the development of interpersonal trust between representatives of the interacting organizations, which is also referred to as intra-entity trust (Fang et al., 2008).

This study aims to further advance the understanding of intra-entity trust by focusing on calculative and relational foundations (Poppo, Zhou, \& Li, 2016) and examining the interplay and patterning of factors from three different domains. Prior work on trust-enhancing 
mechanisms investigates a wide range of factors, with three themes having received strong interest: (1) the interaction process, with a focus on factors such as communication characteristics and past experiences in an exchange relationship (e.g., Anderson \& Narus, 1990); (2) the interacting parties, with a focus on characteristics of the individual or the organization (e.g., Kumar \& Seth, 1998); and (3) the interaction setting, with an emphasis on factors such as interaction intensity (e.g., Crosby, Evans, \& Cowles, 1990).

Drawing on the insights from this prior work, this study aims to contribute to and extend extant knowledge on trust by proposing an integrative position that considers the interplay of factors of all three categories (see Fig. 1). Specifically, this study sheds light on communication styles (i.e., communication proactiveness and communication fuzziness), interactant stereotypes (i.e., employee warmth and employee competence), and interaction structure characteristics (i.e., interaction frequency and interaction duration) to explain high trust.

Insert Fig. 1 here.

Communication refers to "the formal as well as informal sharing of meaningful and timely information" (Anderson \& Narus, 1990, p. 44) and contributes to the development of trust (Morgan \& Hunt, 1994). Through communication, interacting partners can resolve conflicts by learning about each other's expectations and by aligning their goals (Claycomb \& Frankwick, 2004). When a recipient perceives past communication as truthful, the trustworthiness of the information extends to the informant (Moorman, Deshpandé, \& Zaltman, 1993). Two communication styles appear to have a special role within this context: communication proactiveness and communication fuzziness. Communication proactiveness refers to an informant's self-initiated, long-term-focused, and persistent behavior toward an interaction partner (Rank, Carsten, Unger, \& Spector, 2007), while communication fuzziness refers to an 
informant's unclear and vague response to an interaction partner's request that compromises the clarity of the desired information (Bickart, Morrin, \& Ratneshwar, 2015).

Beyond these communication-related factors, this study also considers characteristics of the interactants. Drawing on the stereotype content model (Fiske, Cuddy, Glick, \& Xu, 2002) and empirical research on stereotyping, this study sheds light on the concepts of employee warmth and employee competence as perceived by clients. According to the stereotype content model, people tend to organize the way they perceive others on warmth and competence stereotypes, that is, blanket judgments containing evaluative components. Warmth covers issues such as friendliness, helpfulness, sincerity, and trustworthiness, and competence reflects issues such as intelligence, skill, and efficacy (Fiske, Cuddy, \& Glick, 2007). The stereotypes arise from evaluations of the potential benefit or harm of others' goals and the extent to which others have the ability to realize these goals (Cuddy, Fiske, \& Glick, 2007). While other people perceived as having positive and cooperative intentions are stereotyped as warm, those perceived as having negative and competitive intentions are stereotyped as cold (Cuddy et al., 2007). Furthermore, other people perceived as having the ability to implement their intentions are stereotyped as competent, while those perceived as being unable to accomplish goals are stereotyped as incompetent (Cuddy et al., 2007).

The final domain considered herein is that of interaction structure. Factors of interaction structure can exert a direct impact on the development of trust (e.g., Doney \& Cannon, 1997; Palmatier et al., 2006). The analysis includes two interaction structure characteristics: interaction frequency and interaction duration. Interaction frequency refers to the number of contacts in a period (Dagger, Danaher, \& Gibbs, 2009), and interaction duration reflects the time spent per interaction. Frequent and/or long interactions between two interacting partners signal a 
willingness to work together (Crosby et al., 1990) and provide the opportunity to learn about each other's expectations and goals (Paulssen et al., 2016).

Two key questions that derive from the preceding discussion are how these different factors work together and complement each other and what combinations of these factors contribute to the development of interpersonal trust. This study aims to answer these questions by adopting an exploratory perspective to unmask potential trust-enhancing mechanisms. Rather than examining the net effects of isolated factors on trust, this study investigates how multiple factors, as described previously, work together and form configurations for achieving high interpersonal trust (e.g., Woodside, 2019).

\section{Research approach}

\subsection{Data collection and sample}

Data for the study came from a self-administered survey of executives who provided information on their relationships with financial advisers located in Germany. The sampling frame consisted of a list of clients of financial service providers. A cover letter invited the respondents to participate in the survey. In addition, the cover letter ensured confidentiality and anonymity and informed the respondents that there were no correct or wrong answers. Seven questionnaires were excluded from the study, because the respondents indicated that they did not have personal contact with a financial adviser. In total, 121 respondents completed the questionnaire, for a response rate of 5\%. Approximately $27 \%$ of the respondents are women. The mean age is 47.4 years $(\mathrm{SD}=10.70)$. Respondents' average tenure with their current position is 12.2 years $(\mathrm{SD}=8.40)$. The mean length of the relationship with the financial adviser is 6.9 years $(\mathrm{SD}=5.61)$. Following Armstrong and Overton $(1977)$, the study assessed potential 
non-response issues by comparing early and late responses. The results of this test indicated no significant mean differences for the focal constructs (i.e., all $p>0.05$ ).

\subsection{Construct measures and measurement validation}

The data collection instrument was a standardized questionnaire. This study measured trust with four items from Dagger et al. (2009). To capture communication proactiveness, the study used three items from Rank et al. (2007). Three items inspired by Bickart et al. (2015) measured communication fuzziness. Employee warmth and competence were captured with three items each from Fiske et al. (2002). This study measured interaction frequency and interaction duration with two items each, considering both personal and phone contacts for each of the two concepts (Paulssen et al. 2016). Finally, the questionnaire asked respondents to report on demographics (i.e., gender and age), tenure with the current position, and the length of the relationship with the financial adviser. Table 1 provides details on the construct measures.

This study assessed reliability, convergent validity, and discriminant validity of the latent constructs following the recommendations in prior work (Bagozzi, Yi, \& Phillips, 1991; Gerbing \& Anderson, 1988) and calculated multiple fit indices, including comparative fit index (CFI), Tucker-Lewis index (TLI), and root mean square error of approximation (RMSEA), to assess the overall measurement model fit. For the overall fit, the results revealed satisfactory values for each of the indices $\left(\chi^{2}=156.35, d f=109, \chi^{2} / d f=1.43 ; \mathrm{CFI}=0.97\right.$; TLI $=0.96$; $\left.\mathrm{RMSEA}=0.06\right)$. In addition, analysis of local parameters indicated that Cronbach's alphas ranged from 0.78 to 0.93 and exceed the standard threshold of 0.7 (Nunnally, 1978). Furthermore, composite reliability ranged from 0.80 to 0.93 , and average variance extracted ranged from 0.58 to 0.78 . These values exceed the thresholds of 0.6 and 0.5, respectively (Bagozzi \& Yi, 1988). Analysis of discriminant validity according to the procedure Fornell and Larcker (1981) suggest showed 
that the average variance extracted by the measure of each factor was higher than the squared correlation of that factor with all other factors in the model. These results indicate satisfactory discriminant validity (see Table 2). In summary, the results show that the measurement model fits the data well. For subsequent analyses, this study combined the multiple-item measures of the focal constructs, aggregated the interaction frequencies, and averaged the interaction durations.

Insert Tables 1 and 2 here.

\subsection{Data analysis}

\subsubsection{Overview of analytic approach}

To explain high trust, fsQCA helped examine the complex patterns among communication styles, interactant stereotypes, and interaction structure characteristics. The fsQCA builds on the premise that relationships between different conditions (i.e., antecedent conditions and the outcome condition) can be expressed in terms of set membership and set relations (Fiss, 2011; Ragin, 2008). This analysis examines how membership of cases in the sets of antecedent conditions or combinations thereof is linked to membership in the outcome set. It also examines the connections between antecedent conditions and the outcome condition in terms of necessity and sufficiency (Ragin, 2008). Necessity means that an antecedent condition must be present for an outcome, and sufficiency means that an antecedent condition (or a combination of antecedent conditions) can bring about an outcome (Ragin, 2008).

In line with recommendations in the literature (Fiss, 2011; Ragin, 2008; Schneider \& Wagemann, 2010), this study performed the analysis in three steps. First, this study calibrated the construct measures to obtain each case's membership scores in the sets of antecedent conditions and the outcome set. The fsQCA encompasses six antecedent conditions: communication 
proactiveness, communication fuzziness, employee warmth, employee competence, interaction frequency, and interaction duration. The outcome of interest is high trust. Second, this study performed an analysis of necessity to examine whether any of the antecedent conditions is an indispensable prerequisite for high trust. Third, this study examined sufficient (combinations of) antecedent conditions for high trust.

\subsubsection{Calibration}

The fsQCA requires the calibration of fuzzy sets, which entails transforming construct measures into fuzzy-set membership scores. Following Ragin (2008), this study specified thresholds for full membership in the fuzzy sets, thresholds for full non-membership in the fuzzy sets, and crossover points to structure the calibration, using the direct method of calibration (Ragin, Drass, \& Davey, 2006).

For communication proactiveness, the threshold 7 (on a 7-point scale) indicates full membership in the set of proactive communication, the threshold 1 indicates full nonmembership, and the value 4 (the scale midpoint) indicates the crossover point. The same rules apply for the calibration of membership in the sets of communication fuzziness, employee warmth, and employee competence. For the calibration of the outcome, the threshold 7 (the scale maximum) indicates full membership, the threshold 4 (the scale midpoint) indicates full nonmembership, and the value 5.5 (the halfway mark between the scale maximum and the scale midpoint) indicates the crossover point for high trust in a business relationship. This approach ties set membership to the level of agreement that respondents indicate for the particular items reflecting the domain of interest.

For the calibration of interaction frequency, this study sets the threshold for membership in the set of frequent interactions at value 52, which means that all interactions that take place more 
often than once a week are fully in the set of frequent interactions. The threshold for full nonmembership is value 1 , which indicates that interactions that take place less than once a year are fully out of the set of frequent interactions. The crossover point at value 12 , reflects an interaction frequency of once per month.

For the calibration of interaction duration, this study sets the threshold for membership in the set of long interactions at value 90, which means that all interactions that last more than 90 minutes on average are fully in the set of long interactions. The threshold for full nonmembership is value 5, which indicates that interactions that take less than five minutes are fully out of the set of long interactions. The crossover point at value 30 reflects an average interaction duration of half an hour.

To avoid fuzzy-set scores of 0.5 that exactly meet the crossover point and cause difficulties when intersecting sets (Ragin, 2008), the study added a constant of 0.001 to all scores below full membership (Fiss, 2011). The fs/QCA software program (Ragin et al., 2006), which includes commands for the calibration of fuzzy sets, helped obtain the fuzzy-set scores for all relevant conditions.

\subsubsection{Analysis of necessity}

To examine whether any of the antecedent conditions is a necessary condition for high trust, this study performed an analysis of necessity. Necessity means that for each empirical case, the fuzzy-set membership score of the outcome is lower than the fuzzy-set membership score of the antecedent condition (and the antecedent condition set is thus a superset of the outcome set). This rule typically does not hold for all empirical cases. Therefore, prior work suggests the use of consistency scores, which indicate the degree to which the empirical data are in line with a superset relation (Ragin, 2006). A condition is necessary or "almost always necessary" if the 
consistency score exceeds the threshold of 0.9 (e.g., Leischnig, Ivens, \& Henneberg, 2015). For a consistent necessary condition, coverage indicates the constraining effect of that condition on the outcome of interest. When the coverage of a necessary condition by the outcome is high (low), the constraining effect of this necessary condition is strong (weak) (Ragin, 2006).

\subsubsection{Analyses of sufficiency}

Sufficiency analysis helps disentangle patterns of communication styles, interactant stereotypes, and interaction structure characteristics for high trust. The first step of this analysis included the construction of a truth table that represents all logically possible combinations of the six antecedent conditions. This truth table was then simplified on the basis of frequency and consistency thresholds (Fiss, 2011; Ragin, 2008). Frequency refers to the number of empirical cases covering a particular combination of antecedent conditions. The definition of a frequency cutoff implies that the analysis occurs only for combinations of antecedent conditions that achieve a minimum level of empirical representation. The frequency threshold of 3 used herein ensured that $80 \%$ of all the empirical cases were part of the analyses and that combinations with lower empirical representation were treated as logical remainders (Greckhamer, Misangyi, \& Fiss, 2013).

To distinguish configurations that consistently lead to high trust from those that do not, this study set the minimum acceptable level of consistency at 0.83 , which exceeds the commonly used threshold of 0.8 (Ragin, 2008). This value was obtained through inspection of the ordered consistency scores and corresponds to a dip in the scores at value 0.83 (Schneider \& Wagemann, 2010).

For a sufficiency analysis, fsQCA reports three types of solutions or models: the parsimonious, the intermediate, and the complex solution. These models differ in the extent to 
which logical remainders were considered in the analysis. This study focuses on the parsimonious solution obtained by the analysis, as "[o]nly maximally parsimonious solution formulas can represent causal structures" (Baumgartner, 2015, p. 840).

\section{Findings and post hoc analysis}

\subsection{Findings of the analyses}

Table 3 summarizes the results of the necessity analysis and reports both consistency scores and coverage scores for the particular antecedent conditions and their negations. In an analysis of necessity, consistency reflects the degree to which the empirical data are in line with a superset relation, and coverage scores offer insights into the relevance and trivialness of a necessary condition (Ragin, 2006). The results of the analysis indicate that the consistency scores for two conditions (i.e., the presence of employee competence and the negation of communication fuzziness) exceed the threshold value of 0.9. Therefore, these two conditions are necessary for high trust. The coverage scores of these conditions are 0.68 and 0.67 , respectively, which indicates that these consistent necessary conditions are non-trivial.

Table 4 shows the results of the sufficiency analysis based on the parsimonious solution obtained by the fsQCA. The analysis indicates the existence of one model consisting of two configurations sufficient for high trust. Configuration 1 combines the presence of communication proactiveness with employee warmth. Configuration 2 combines the presence of employee warmth and interaction frequency with the absence of communication fuzziness.

In addition to these configurations, Table 4 shows consistency and coverage scores for the overall solution and for each of the two configurations. In an analysis of sufficiency, consistency highlights the significance of a subset relation, and coverage indicates the proportion of cases that involve a particular configuration in bringing about the outcome in question (Ragin, 2006). 
The overall solution consistency score is 0.78 , and the consistency scores for the particular configurations are 0.79 and 0.81 , respectively. Furthermore, the combined model has an overall coverage score of 0.74 , which indicates that the configurations account for almost $75 \%$ of membership in the outcome, with raw coverage scores for the particular configurations ranging between 0.51 and 0.70 .

Insert Tables 3 and 4 here.

\subsection{Post hoc analysis}

Recent research shows that configurational comparative studies can be subject to model ambiguity as a result of the minimization principles used by the Quine-McCluskey algorithm (Baumgartner \& Thiem, 2017). Model ambiguity refers to a situation in which the causal model space for an outcome consists of more than one model. To assess the possible existence of model ambiguity, this study re-analyzed the data using QCApro, which uses the enhanced QuineMcCluskey algorithm (Thiem, 2018). The re-analysis of the data indicates that, in addition to the solution obtained through the fsQCA, two other models exist, with each including two configurations for the outcome under investigation. Table 5 summarizes the results of the post hoc analysis.

Insert Table 5 here.

\section{Discussion}

\subsection{Theoretical contributions}

The formation of trust in interorganizational relationships is a multi-stage process characterized by cross-level effects (Schilke \& Cook, 2013). The purpose of this study was to contribute to extant trust literature by focusing on one of the key stages of the trust formation process, namely the development of interpersonal (intra-entity) trust between representatives of 
the interacting organizations. A more detailed analysis of this stage is important because it determines subsequent trust transfer processes and, thus, the nature and degree of eventual interorganizational trust.

In an attempt to better understand how interpersonal trust develops in organizational settings, this study investigated factors of three important domains (i.e., communication style, interactant stereotypes, and interaction structure) that can be conceived as calculative and relational foundations for trust formation. The results of the analysis reveal that the presence of employee competence and the absence of communication fuzziness are necessary conditions for high trust. These findings offer new insights into trust-related hygiene factors - that is, prerequisites that need to be met to gain high intra-entity trust — and suggest that calculative factors have an important role. The findings thus contribute to cognition-based trust research by uncovering two essential calculative prerequisites for trust.

In addition, the results of the fsQCA and the post hoc analysis indicate four alternative configurations for achieving high trust. These configurations indicate different pathways to high trust with varying empirical relevance. Of the four configurations, configuration 2 has the highest empirical relevance (as indicated by a raw coverage score of 0.7 ) and thus is discussed in more detail. This configuration shows that clients experience a high level of trust when they perceive advisers as warm and when the advisers use a proactive communication approach. According to the stereotype content model, the perception of others as competent and warm can stimulate emotional responses of admiration and pride (Fiske et al., 2002). This alone, however, is insufficient for achieving high trust. An additional ingredient required for high trust is a proactive communication approach, which implies that informant characteristics unfold their trust-enhancing effects when accompanied by particular interaction process characteristics that 
ensure an open dissemination of relevant information. Interaction structural characteristics (here interaction frequency and duration) have a subordinate role in this configuration.

In summary, the insights obtained from the fsQCA delineate important trust-enhancing mechanisms and shed light on different complementarity effects among communication-, interactant-, and interaction structure-related factors. These findings contribute to the trust literature by illuminating compound causes and revealing multiple realities (Woodside, 2014) for achieving high trust. They also add to the literature on interpersonal approaches to increase relationship quality dimensions (e.g., Leischnig, Kasper-Brauer, \& Thornton, 2018).

\subsection{Managerial implications}

The findings of this study have two key messages for managers. First, the presence of employee competence and the absence of communication fuzziness are hygiene factors for high trust. Thus, managers who wish to achieve trustful relationships between clients and advisers should ensure that frontline employees effectively signal competence and communicate in an unambiguous and clear way with clients. Training programs that focus on both employees' factual knowledge and their communication skills might help accomplish these goals.

Second, alternative pathways to high interpersonal trust exist. These pathways prioritize different factors and offer choices for managers in the design of interaction approaches. For example, configuration 2 indicates subordinate roles for interaction frequency and interaction duration. As these two factors can interfere with efficiency (vs. effectiveness) goals, managers who want to accomplish both high trust and high efficiency in interpersonal interactions might opt for configuration 2 and develop employee training and education programs that improve the competences and skills shown in this configuration. 


\section{References}

Achrol, R. S., \& Stern, L. W. (1988). Environmental determinants of decision-making uncertainty in marketing channels. Journal of Marketing Research, 25(1), 36-50.

Anderson, J. C., \& Narus, J. A. (1990). A model of distributor firm and manufacturer firm working partnerships. Journal of Marketing, 54(1), 42-58.

Armstrong, J. S., \& Overton, T. S. (1977). Estimating nonresponse bias in mail surveys. Journal of Marketing Research, 14(3), 396-402.

Arrow, K. J. (1974). The limits of organization. New York: W.W. Norton \& Company.

Bagozzi, R. P., \& Yi, Y. (1988). On the evaluation of structural equation models. Journal of the Academy of Marketing Science, 16(1), 74-94.

Bagozzi, R. P., Yi, Y., \& Phillips, L. W. (1991). Assessing construct validity in organizational research. Administrative Science Quarterly, 36(3), 421-458.

Baumgartner, M. (2015). Parsimony and causality. Quality \& Quantity, 49(2), 839-856.

Baumgartner, M., \& Thiem, A. (2017). Model ambiguities in configurational comparative research. Sociological Methods \& Research, 46(4), 954-987.

Bickart, B., Morrin, M., \& Ratneshwar, S. (2015). Does it pay to beat around the bush? The case of the obfuscating salesperson. Journal of Consumer Psychology, 25(4), 596-608.

Claycomb, C., \& Frankwick, G. L. (2004). A contingency perspective of communication, conflict resolution and buyer search effort in buyer $\square$ supplier relationships. Journal of Supply Chain Management, 40(1), 18-34.

Crosby, L. A., Evans, K. R., \& Cowles, D. (1990). Relationship quality in services selling: An interpersonal influence perspective. Journal of Marketing, 54(3), 68-81. 
Cuddy, A. J., Fiske, S. T., \& Glick, P. (2007). The BIAS map: Behaviors from intergroup affect and stereotypes. Journal of Personality and Social Psychology, 92(4), 631-648.

Dagger, T. S., Danaher, P. J., \& Gibbs, B. J. (2009). How often versus how long: The interplay of contact frequency and relationship duration in customer-reported service relationship strength. Journal of Service Research, 11(4), 371-388.

Doney, P. M., \& Cannon, J. P. (1997). An examination of the nature of trust in buyer-seller relationships. Journal of Marketing, 61(2), 35-51.

Fang, E., Palmatier, R. W., Scheer, L. K., \& Li, N. (2008). Trust at different organizational levels. Journal of Marketing, 72(2), 80-98.

Fiske, S. T., Cuddy, A. J. C., \& Glick, P. (2007). Universal dimensions of social cognition: Warmth and competence. Trends in Cognitive Sciences, 11(2), 77-83.

Fiske, S. T., Cuddy, A. J. C., Glick, P., \& Xu, J. (2002). A model of (often mixed) stereotype content: Competence and warmth respectively follow from perceived status and competition. Journal of Personality and Social Psychology, 82(6), 878-902.

Fiss, P. C. (2011). Building better causal theories: A fuzzy set approach to typologies in organization research. Academy of Management Journal, 54(2), 393-420.

Fornell, C., \& Larcker, D. F. (1981). Evaluating structural equation models with unobservable variables and measurement error. Journal of Marketing Research, 18(1), 39-50.

Ganesan, S. (1994). Determinants of long-term orientation in buyer-seller relationships. Journal of Marketing, 58(2), 1-19.

Gerbing, D. W., \& Anderson, J. C. (1988). An updated paradigm for scale development incorporating unidimensionality and its assessment. Journal of Marketing Research, 25(2), 186-192. 
Greckhamer, T., Misangyi, V. F., \& Fiss, P. C. (2013). The two QCAs: From a small-N to a large-N set theoretic approach. In P. C. Fiss, B. Cambré, \& A. Marx (Eds.), Configurational theory and methods in organizational research. Research in the sociology of organizations (Vol. 38, pp. 49-75). Bingley, UK: Emerald.

Gulati, R. (2007). Managing network resources: Alliances, affiliations, and other relational assets. Oxford: Oxford University Press.

Gulati, R., \& Nickerson, J. A. (2008). Interorganizational trust, governance choice, and exchange performance. Organization Science, 19(5), 688-708.

Jap, S. D., \& Anderson, E. (2003). Safeguarding interorganizational performance and continuity under ex post opportunism. Management Science, 49(12), 1684-1701.

Kumar, S., \& Seth, A. (1998). The design of coordination and control mechanisms for managing joint venture-parent relationships. Strategic Management Journal, 19(6), 579-599.

Leischnig, A., Ivens, B. S., \& Henneberg, S. C. (2015). When stress frustrates and when it does not: Configural models of frustrated versus mellow salespeople. Psychology \& Marketing, 32(11), 1098-1114.

Leischnig, A., Kasper-Brauer, K., \& Thornton, S. C. (2018). Spotlight on customization: An analysis of necessity and sufficiency in services. Journal of Business Research, 89, 385390.

Moorman, C., Deshpandé, R., \& Zaltman, G. (1993). Factors affecting trust in market research relationships. Journal of Marketing, 57(1), 81-101.

Morgan, R. M., \& Hunt, S. D. (1994). The commitment-trust theory of relationship marketing. Journal of Marketing, 58(3), 20-38.

Nunnally, J. C. (1978). Psychometric theory. New York: McGraw-Hill. 
Palmatier, R. W., Dant, R. P., Grewal, D., \& Evans, K. R. (2006). Factors influencing the effectiveness of relationship marketing: A meta-analysis. Journal of Marketing, 70(4), 136153.

Paulssen, M., Leischnig, A., Ivens, B. S., \& Birk, M. M. (2016). Relational norms in customercompany relationships: Net and configurational effects. Journal of Business Research, 69(12), 5866-5874.

Poppo, L., Zhou, K. Z., \& Li, J. J. (2016). When can you trust "trust"? Calculative trust, relational trust, and supplier performance. Strategic Management Journal, 37(4), 724-741.

Puranam, P., \& Vanneste, B. S. (2009). Trust and governance: Untangling a tangled web. Academy of Management Review, 34(1), 11-31.

Ragin, C. C. (2006). Set relations in social research: Evaluating their consistency and coverage. Political Analysis, 14(3), 29-310.

Ragin, C. C. (2008). Redesigning social inquiry: Fuzzy sets and beyond. Chicago: University of Chicago Press.

Ragin, C. C., Drass, K. A., \& Davey, S. (2006). Fuzzy-set/qualitative comparative analysis. Tucson, AZ: Department of Sociology, University of Arizona.

Rank, J., Carsten, J. M., Unger, J. M., \& Spector, P. E. (2007). Proactive customer service performance: Relationships with individual, task, and leadership variables. Human Performance, 20(4), 363-390.

Scheer, L. K., \& Stern, L. W. (1992). The effect of influence type and performance outcomes on attitude toward the influencer. Journal of Marketing Research, 29(1), 128-142.

Schilke, O., \& Cook, K. S. (2013). A cross-level process theory of trust development in interorganizational relationships. Strategic Organization, 11(3), 281-303. 
Schneider, C. Q., \& Wagemann, C. (2010). Standards of good practice in qualitative comparative analysis (QCA) and fuzzy-sets. Comparative Sociology, 9(3), 397-418.

Schoorman, F. D., Mayer, R. C., \& Davis, J. H. (2007). An integrative model of organizational trust: Past, present, and future. Academy of Management Review, 32(2), 344-354.

Smith, K. G., Carroll, S. J., \& Ashford, S. J. (1995). Intra- and inter-organizational cooperation: Toward a research agenda. Academy of Management Journal, 38(1), 7-23.

Thiem, A. (2018). QCApro: Advanced functionality for performing and evaluating qualitative comparative analysis. R package version 1.1-2. Retreived from http://www.alrikthiem.net/software/.

Woodside, A. G. (2014). Embrace • perform • model: Complexity theory, contrarian case analysis, and multiple realities. Journal of Business Research, 67(12), 2495-2503.

Woodside, A. G. (2019). Focusing on case outcomes rather than variable relationships. In H. Akrout, K. Raies, \& A. G. Woodside (Eds.), New insights on trust in business-to-business relationships. A multi-perspective approach (pp. ix-xiii). Bingley, UK: Emerald.

Zaheer, A., \& Venkatraman, N. (1995). Relational governance as an interorganizational strategy: An empirical test of the role of trust in economic exchange. Strategic Management Journal, 16(5), 373-392.

Zheng, S., Hui, S. F., \& Yang, Z. (2017). Hospital trust or doctor trust? A fuzzy analysis of trust in the health care setting. Journal of Business Research, 78, 217-225. 
Fig. 1. Conceptual framework.

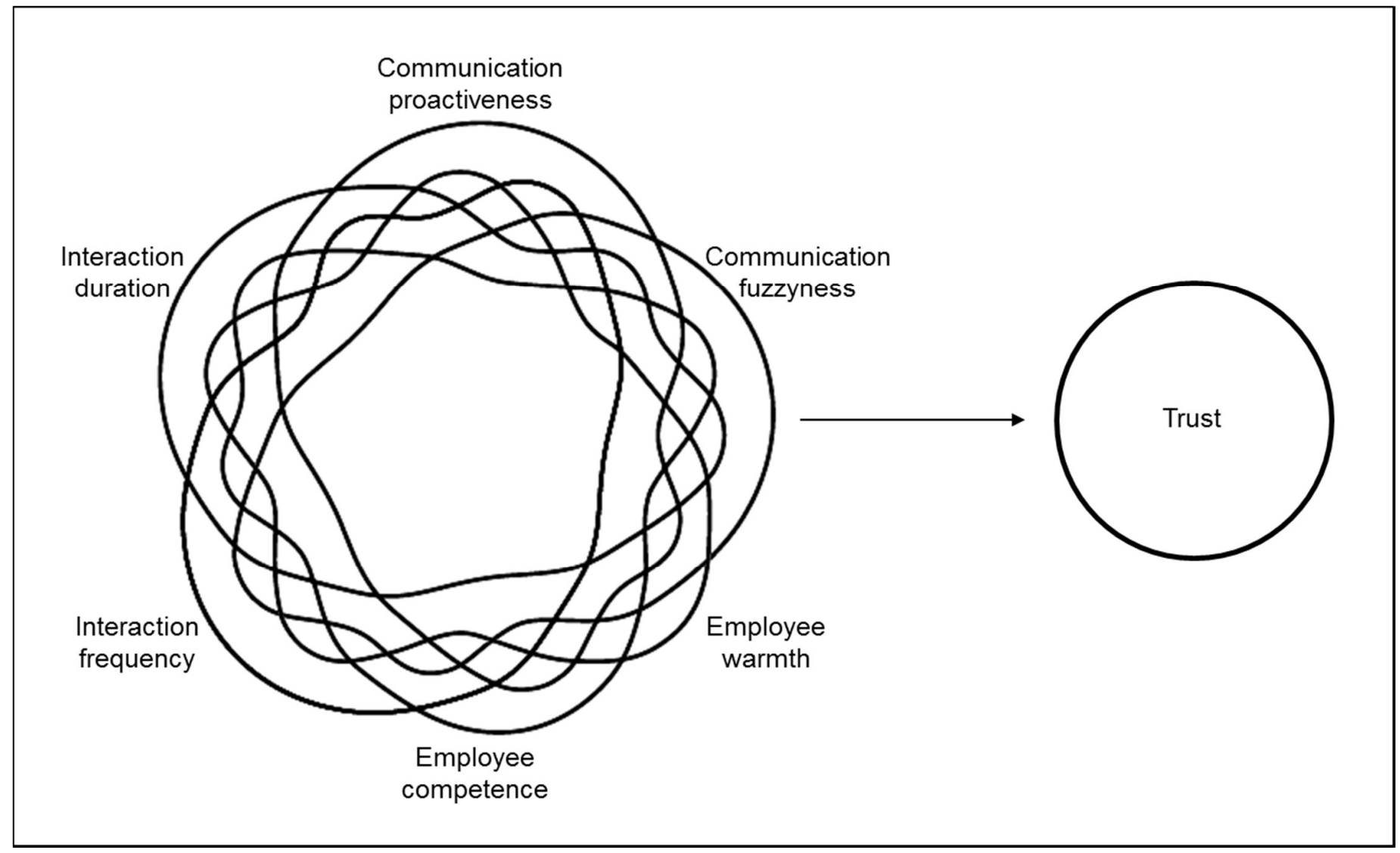




\section{Table 1}

Information on construct measures.

Trust $(\mathrm{CA}=0.91 ; \mathrm{CR}=0.91 ; \mathrm{AVE}=0.72)$

To what extent do you agree with the following statements?

Scale: 1 = "completely disagree," 7 = "completely agree"

This financial advisor can be trusted.

This financial advisor can be counted on to do what is right

This financial advisor has high integrity.

This financial advisor is trustworthy.

Communication proactiveness $(\mathrm{CA}=0.88 ; \mathrm{CR}=0.88 ; \mathrm{AVE}=0.72)$

To what extent do you agree with the following statements?

Scale: 1 = "completely disagree," 7 = "completely agree"

My financial advisor member proactively shares information with me to meet my needs.

My financial advisor anticipates potential issues and proactively develops solutions.

My financial advisor uses own judgment to make exceptions or improvise solutions.

Communication fuzziness $(\mathrm{CA}=0.93 ; \mathrm{CR}=0.93 ; \mathrm{AVE}=0.78)$

To what extent do you agree with the following statements?

Scale: 1 = "completely disagree," 7 = "completely agree"

My financial advisor leaves some questions unanswered.

My financial advisor beats around the bush.

My financial advisor makes unclear and fuzzy statements.

My financial advisor sometimes evades my questions.

Employee warmth $(\mathrm{CA}=0.82 ; \mathrm{CR}=0.83 ; \mathrm{AVE}=0.62)$

To what extent do you agree with the following statements?

Scale: 1 = "completely disagree," 7 = "completely agree"

Tolerant

Warm

Good-natured

Employee competence $(\mathrm{CA}=0.78 ; \mathrm{CR}=0.80 ; \mathrm{AVE}=0.58)$

To what extent do you agree with the following statements?

Scale: 1 = "completely disagree," 7 = "completely agree"

Competent

Intelligent

Confident

Interaction frequency $(\mathrm{CA}=$ n.a.; $\mathrm{CR}=$ n.a.; $\mathrm{AVE}=$ n.a. $)$ 
How often are you in contact with your financial adviser via the following channels?

Direct personal contact

Phone contact

Interaction duration $(\mathrm{CA}=$ n.a.; $\mathrm{CR}=$ n.a.; $\mathrm{AVE}=$ n.a. $)$

How long does a typical contact last [in minutes]?

Direct personal contact

Phone contact

Notes: $\mathrm{CA}=$ Cronbach's alpha; $\mathrm{CR}=$ composite reliability; $\mathrm{AVE}=$ average variance

extracted; n.a. $=$ not applicable. 
Table 2

Correlations and discriminant validity.

\begin{tabular}{lccccccccc}
\hline & $\mathrm{M}$ & $\mathrm{SD}$ & 1 & 2 & 3 & 4 & 5 & 6 & 7 \\
\hline Trust & 5.52 & 1.15 & 0.72 & & & & & & \\
Communication proactiveness & 4.31 & 1.54 & 0.23 & 0.72 & & & & & \\
Communication fuzziness & 2.28 & 1.40 & 0.28 & 0.17 & 0.76 & & & & \\
Employee warmth & 4.62 & 1.17 & 0.12 & 0.10 & 0.08 & 0.62 & & & \\
Employee competence & 5.52 & 1.03 & 0.32 & 0.15 & 0.43 & 0.09 & 0.60 & & \\
Interaction frequency & 17.77 & 30.20 & 0.00 & 0.02 & 0.02 & 0.00 & 0.00 & $-^{\mathrm{a}}$ & \\
Interaction duration & 28.44 & 22.02 & 0.00 & 0.01 & 0.01 & 0.01 & 0.08 & 0.01 & $-^{\mathrm{a}}$ \\
\hline
\end{tabular}

Notes: AVE is on the diagonal; squared inter-construct correlations are below the diagonal; ${ }^{\text {a }}$ single-item measures. 
Table 3

Results of analyses of necessity.

\begin{tabular}{lcc}
\hline Conditions & Consistency & Coverage \\
\hline Communication proactiveness (proac) & 0.78 & 0.75 \\
Communication fuzziness (fuzzy) & 0.22 & 0.59 \\
Employee warmth (warm) & 0.81 & 0.71 \\
Employee competence (comp) & 0.96 & 0.68 \\
Interaction frequency (freq) & 0.56 & 0.72 \\
Interaction duration (dur) & 0.49 & 0.70 \\
$\sim$ Communication proactiveness & 0.50 & 0.63 \\
$\sim$ Communication fuzziness & 0.96 & 0.67 \\
$\sim$ Employee warmth & 0.48 & 0.70 \\
$\sim$ Employee competence & 0.27 & 0.67 \\
Interaction frequency & 0.70 & 0.68 \\
Interaction duration & 0.74 & 0.66 \\
\hline
\end{tabular}

Notes: Necessity consistency threshold $=0.9$. 


\section{Table 4}

Results of analyses of sufficiency.

\begin{tabular}{lccccc}
\hline Configurations & Consistency & $\begin{array}{c}\text { Raw } \\
\text { coverage }\end{array}$ & $\begin{array}{c}\text { Unique } \\
\text { coverage }\end{array}$ & $\begin{array}{c}\text { Overall } \\
\text { solution } \\
\text { consistency }\end{array}$ & $\begin{array}{c}\text { Overall } \\
\text { solution } \\
\text { coverage }\end{array}$ \\
\hline $1 \quad$ proac $\bullet$ warm + & 0.79 & 0.70 & 0.23 & 0.78 & 0.74 \\
$2 \quad \sim$ fuzzy $\bullet$ warm $\bullet$ freq & 0.81 & 0.51 & 0.04 & & \\
\hline
\end{tabular}

Notes: Frequency cutoff $=3$ ( $79 \%$ of the cases); consistency cutoff $=0.84$; parsimonious solution based on Quine-McCluskey algorithm. 
Table 5

Results of post hoc analysis.

\begin{tabular}{llccccc}
\hline Configurations & Consistency & $\begin{array}{c}\text { Raw } \\
\text { coverage }\end{array}$ & $\begin{array}{c}\text { Unique } \\
\text { coverage }\end{array}$ & Model 1 & Model 2 & Model 3 \\
\hline $1 \quad$ proac $\cdot \sim$ freq & 0.80 & 0.58 & 0.03 & - & - & 0.23 \\
$2 \quad$ proac $\bullet$ warm & 0.79 & 0.70 & 0.04 & 0.23 & 0.42 & - \\
$3 \quad \sim$ fuzzy $\bullet \sim$ proac $\bullet$ freq & 0.81 & 0.34 & 0.01 & - & 0.05 & - \\
$4 \quad \sim$ fuzzy $\bullet$ warm $\bullet$ freq & 0.81 & 0.51 & 0.001 & 0.04 & - & \\
\hline Model 1 & 0.78 & 0.74 & & & \\
Model 2 & 0.78 & 0.76 & & & \\
Model 3 & 0.78 & 0.74 & & & \\
\hline
\end{tabular}

Notes: Frequency cutoff $=3$ ( $79 \%$ of the cases $)$; consistency cutoff $=0.84$; parsimonious solution based on enhanced Quine-McCluskey algorithm. 